\title{
Stimulus-response compatibility as a determinant of interference in a Stroop-like task
}

\author{
ELAINE FOX \\ Victoria University of Wellington, Wellington, New Zealand \\ (Murray J. White, Sponsor)
}

\begin{abstract}
The contribution of stimulus-response compatibility (SRC) to interference effects was tested in a Stroop-like task. Few previous studies have examined maximal compatibility for both dimensions of a stimulus. In the present study, the words UP, DOWN, LEFT, and RIGHT were presented on a computer screen. The word appeared at fixation and immediately began to move either up or down or left or right. Subjects responded either manually (by moving a joystick) or verbally according to (1) the verbal denotation of the word or (2) the direction the word was moving. Stimuli were congruent (e.g., UP moving up) or incongruent (e.g., UP moving down) and were presented in four conditions that varied in the degree of SRC (e.g., voice response to the meaning of the word = high SRC; voice response to the direction the word was moving = low SRC). Response times were slower in conditions with low SRC. The typical congruency effect was more pronounced in conditions with low SRC than in conditions with high SRC, showing that at least some of the interference observed in Stroop-type studies can be explained in terms of SRC.
\end{abstract}

In the traditional Stroop task, names of colors are written in different colored inks (Stroop, 1935). When subjects are asked to read the word, they encounter little interference from an incongruent ink color, whereas when they are asked to name the ink color, they experience significant interference from an incongruent word (Dyer, 1973; MacLeod, 1991).

A number of studies have shown that Stroop interference can be significantly reduced by using non-naming responses such as buttonpressing (Flowers \& Dutch, 1976; Keele, 1972; Virzi \& Egeth, 1985). A possible explanation is that a printed word is "a program for a reader telling him how to pronounce it, but an object is not related to its name except arbitrarily"' (Beller, 1975, p. 155). In other words, a nonverbal response is not compatible with a verbal stimulus, and therefore verbal incongruency does not produce interference. Likewise, Treisman and Fearnley (1969) have argued that interference with selective attention or response might arise only when the irrelevant stimulus attribute belongs to the same class as the response. The logical conclusion of this line of reasoning is that interference effects would be severely reduced if it were possible for subjects to generate a "color" response. This is the hypothesis that guides the present research: when there is maximal compatibility between the irrelevant stimulus dimension (cue) and the required re-

This research was supported by Victoria University of Wellington IGC Grant 485A. I am indebted to Paul Andrews, who wrote the computer program, Steven Haslett, who provided statistical advice, and Tracey Williams, who collected the data. I am particularly grateful to Murray White and also to John McDowall for helpful comments on an earlier draft of this paper. Correspondence should be addressed to E. Fox, Department of Psychology, Victoria University of Wellington, P. O. Box 600, Wellington, New Zealand (e-mail: foxe@matai.vuw.ac.nz). sponse, an incongruent stimulus will produce more interference than when the irrelevant stimulus dimension is less compatible or incompatible with the response.

It is impossible to fully assess the impact of stimulusresponse compatibility (SRC) in the traditional Stroop task as there is no highly compatible (or automatic) response to ink color. A problem with some studies investigating SRC and Stroop interference is that only one dimension of the stimulus was associated with a highly natural or compatible response (e.g., Simon \& Sudalaimuthu, 1979).

It is possible to specifically examine the role of SRC in Stroop interference by increasing the degree of correspondence between the irrelevant stimulus dimension and the response (Flowers, Warner, \& Polansky, 1979; McClain, 1983; Zakay \& Glicksohn, 1985). Flowers et al. (1979) had subjects classify either the numerosity or numeric values of digits or words; responses were indicated by oral naming, card sorting, manual tapping, or oral "tapping" in five separate experiments. When numerosity was the cue for responding, incongruent levels of numeric value slowed naming and sorting but not tapping, whereas when numeric value was the cue, incongruent numerosity slowed tapping but not naming and sorting. Clearly changes in the relative structural similarity between the stimulus and the response may critically alter the ability to ignore an irrelevent stimulus dimension. The role of SRC has been directly examined by McClain (1983). She presented the words HIGH and LOW in high and low pitches with either the pitch or the word being designated the relevant dimension. Responses were verbal, or a buttonpress, or a pitched hum. Significant interference occurred in the incompatible conditions (i.e., pitch-verbal, word-hum, pitch-button), but not in the compatible conditions (pitch-hum, word-verbal, word- 
button). In other words, interference effects occurred when the irrelevant stimulus dimension was highly compatible with the response and were eliminated when the irrelevant stimulus dimension and required response were maximally incompatible. Furthur evidence for the role of SRC in Stroop interference was reported by Zakay and Glicksohn (1985). They had 20 pianists respond to musical notes by either naming or playing the note on a piano. Results indicated that the degree of SRC (high or low) and congruency (high or low) were both significant determinants of response times. The greatest interference effects were observed when both these factors were low, that is, when the stimulus and response were incompatible (e.g., verbally reading a note from note symbols) and when both dimensions of the stimulus were incongruent.

In the present experiment, the stimuli were the words UP, DOWN, LEFT, and RIGHT, which could move in any of these directions on a computer screen. There were four conditions: (1) move the joystick in the direction the word is moving, (2) move the joystick in the direction the word "says," (3) name the direction the word is moving, and (4) name the word. Thus, there were two conditions with high SRC and low cue-response compatibility (CRC): (1) voice response to meaning of word and (2) directional response to direction of movement and two conditions with low SRC and high CRC: (1) voice response to direction of movement and (2) directional response to meaning of word. The experiment conditions are shown in the upper part of Table 1. Both dimensions of the stimulus (word meaning and direction of movement) were either congruent (e.g., UP moving up) or incongruent (e.g., LEFT moving right). An advantage of this paradigm is the relative integration of both dimensions of the stimulus. Although stimulus integration may not be a critical factor (e.g., Neely, 1991), it is important to test SRC and interference effects with stimuli that are as analogous as possible to the traditional color-word stimulus, which is of course highly integrated (see MacLeod, 1991, p. 175).

Table 1

Stimulus-Response Conditions in the Experiment

\begin{tabular}{|c|c|c|c|c|}
\hline & \multicolumn{4}{|c|}{ Internal Stimulus Relationships } \\
\hline & Congruent & Incongruent & Congruent & Incongruent \\
\hline Relevant cue & $\uparrow$ & $\uparrow$ & Up & Left \\
\hline \multirow[t]{2}{*}{ Irrelevant cue } & Up & Down & $\uparrow$ & $\rightarrow$ \\
\hline & \multicolumn{4}{|c|}{ Correct Responses } \\
\hline \multirow[t]{2}{*}{ Joystick } & $\uparrow$ & $\uparrow$ & $\uparrow$ & $\leftarrow$ \\
\hline & (421) & $(421)$ & (520) & $(582)$ \\
\hline Voice & $\underset{(531)}{U p}$ & $\underset{(597)}{U p}$ & $\underset{(470)}{U p}$ & $\begin{array}{c}\text { Left } \\
(492)\end{array}$ \\
\hline
\end{tabular}

Note-Arrows denote direction of movement, and words denote word meaning. Mean correct RTs (msec) are shown in parentheses.
It is predicted that maximal interference will occur in conditions with low SRC and high CRC. For example, when a subject is asked to respond to the direction a word is moving, greater interference to an incongruent stimulus is expected when the response is to name the direction than when the response is to move a joystick in the direction of movement. Likewise, when the task is to respond to word meaning, greater interference is expected when the response is to move a joystick than when the response is verbal.

\section{METHOD}

\section{Subjects}

Subjects were 32 undergraduate students ( 20 male, 12 female) who were paid $\$ 5$ for their participation in the experiment. All subjects had normal or corrected-to-normal vision. Four of the subjects were lefthanded, the remainder were right-handed, and all subjects scored above 45 on the Left-Right Test (Semmes, Weinstein, Ghent, \& Teuber, 1963), which is a standard assessment of spatial (left-right) orientation.

\section{Apparatus}

A Commodore PC-50-II computer controlled the timing, stimulus presentation, and data collection. The stimuli were the words UP, DOWN, LEFT, and RIGHT. All stimuli were in white lettering, centered in a black $2 \mathrm{~cm} \times 1.5 \mathrm{~cm}$ block on a white background. Each stimulus appeared in the center of the screen and immediately began moving (UP/DOWN moving up or down, LEFT/RIGHT moving left or right). The stimulus moved at a constant rate of $8 \mathrm{~cm} / \mathrm{sec}$ and was present until the subject responded, up to a limit of $1,000 \mathrm{msec}$. The subjects responded by moving a joystick in one of the four directions or by naming the direction. The joystick and microphone were interfaced with the computer by a microswitch. A hand-held switch controlling the onset of each trial was also connected to the computer.

\section{Procedure}

The subjects were tested in a single experimental session lasting approximately $40 \mathrm{~min}$. All subjects completed the Left-Right Test to ensure that they had no difficulties making left-right judgments. The microphone was then pinned to the subject's chest and calibrated.

Each subject had 16 practice trials before each condition ( 2 examples of each stimulus type), in which feedback about accuracy and reaction time (RT) was given. In the experimental trials, no feedback was given and the subject controlled the onset of each presentation by means of a hand-held switch. The trial sequence was as follows: (1) a "Get Ready" sign appeared at the center of the screen for $395 \mathrm{msec}$; (2) there was an interval of $720 \mathrm{msec}$; and (3) the stimulus appeared at the center of the screen and immediately began moving. The stimulus disappeared when the subject responded, or after $1,000 \mathrm{msec}$ if there was no response. The basic datum for each presentation was the time taken to respond to the stimulus. The computer recorded the latency from the onset of the stimulus to the response (yoice or joystick) to an accuracy of $5.6 \mathrm{msec}$. For voice conditions, errors were recorded on the computer by the experimenter.

\section{Design}

The experimental design was counterbalanced as follows: Order effects were minimized by using a Latin square for the four conditions. Half of the subjects received the joystick conditions first, and half received the voice conditions first. Responding to the meaning of the word or to the direction of movement of the word was counterbalanced within joystick and voice conditions. There were eight stimulus types (four congruent, four incongruent): UP moving up, UP moving down, DOWN moving down, DOWN moving up, LEFT moving left, LEFT moving right, RIGHT moving right, RIGHT moving left. Each stimulus type was presented 15 times in each condition in a predetermined, randomly generated sequence. Therefore, there were $8 \times 15=120$ stimulus pre- 
sentations in each condition, giving a total of 480 presentations per subject.

\section{RESULTS}

Errors were made on 693 trials (4\%), with over half occurring on incongruent trials. For conditions with a joystick response (joystick + movement, joystick + word), $2 \%$ errors were made, and all of these were due to no response being given in the time allowed. There were more errors in conditions with voice response, most being due to mechanical failure of the microphone. For the condition with voice response to movement, there were $10 \%$ errors; of these, $4.3 \%$ were due to subjects' saying the wrong word and $5.36 \%$ were due to mechanical failure. For voice response to word meaning, there were $5 \%$ errors, of which $1.77 \%$ were due to subjects' saying the wrong word and $3.28 \%$ were due to mechanical failure. Because of the relatively low error rate and because there was no indication of a speed-accuracy tradeoff, only statistical analysis of RT will be presented.

Preliminary analysis showed that there were no RT differences between males and females $[F(1,30)<1]$ and there were no interactions between sex and congruency and conditions. Sex was therefore not included as a factor in the analysis.

The subjects' mean RTs for correct trials are shown in the lower part of Table 1. The data were reduced to congruent and incongruent stimuli collapsed over direction of movement for each subject. A repeated measures analysis of variance (ANOVA) had two factors: conditions (joystick response to direction of movement, joystick response to word meaning, voice response to direction of movement, voice response to word meaning) and congruency (congruent versus incongruent), with subject interaction as the error term. The overall effect of conditions was significant $\left[F(3,93)=99.3, M S_{\mathrm{e}}=163,249\right.$, $p<.001]$. The fastest responses occured with a joystick reponse to direction of movement $(421 \mathrm{msec})$, followed by a voice response to word meaning $(481 \mathrm{msec})$, joystick response to word meaning $(551 \mathrm{msec})$, and a voice response to direction of movement $(564 \mathrm{msec})$. Each of these means differed from the others at the .05 level (Scheffé test). Congruency produced a significant main effect $\left[F(1,31)=179.8, M S_{\mathrm{e}}=28,328, p<.001\right]$, reflecting slower responses in incongruent $(523 \mathrm{msec})$ than in congruent $(485 \mathrm{msec})$ trials.

The conditions $\times$ congruency interaction term was also significant $\left[F(3,93)=37.8, M S_{\mathrm{e}}=23,740, p<.001\right]$. This interaction was explored by conducting a simple effects ANOVA (congruent versus incongruent) for each condition separately. For joystick response to direction of movement, there was no congruency effect $(0.8 \mathrm{msec}$; $F<1$ ). However, there were significant congruency effects for joystick response to word meaning [62 $\mathrm{msec}$; $\left.F(1,31)=63.9, M S_{\mathrm{e}}=57,705, p<.001\right]$, voice response to direction of movement [66 msec; $F(1,31)=$ $\left.147.5, M S_{\mathrm{e}}=23,628, p<.001\right]$, and voice response to word meaning $\left[21 \mathrm{msec} ; F(1,31)=51.0, M S_{\mathrm{e}}=\right.$ $8,528, p<.001]$. This interaction between SRC and congruency is shown in Figure 1. The largest interference effects occurred for conditions with low SRC. This result was found for both voice and joystick response modes. In short, the decrement in RT from a task with high SRC to a task with low SRC for congruent and incongruent stimuli, respectively, was $61 \mathrm{msec}$ and $105 \mathrm{msec}$ for a voice response and $99 \mathrm{msec}$ and $160 \mathrm{msec}$ for a joystick response.

\section{DISCUSSION}

This experiment shows that maximal interference occurred in the two conditions with low SRC and high CRC, with less occurring in the two conditions with high SRC and low CRC. In addition, for a joystick response, an irrelevant cue in the same domain (i.e., direction of movement) produced a slower RT than when the irrelevant cue was in another domain (i.e., word meaning). The same result was found for a voice response; an irrelevant cue in the same domain (word meaning) produced a slower RT than an irrelevant cue in a different domain (direction of movement). This result was found for both congruent and incongruent stimuli. Thus, when there is maximal compatibility between an irrelevant stimulus dimension and the required response, an incongruent stimulus produces more interference than when the irrelevant stimulus dimension is less compatible or incompatible with the required response.

A possible explanation of why maximal compatibility between the irrelevant dimension of a stimulus and a response may produce greatest interference is given by C. W. Eriksen's response-competition notion (B. A. Eriksen \& C. W. Eriksen, 1974; C. W. Eriksen, Coles, Morris, \& O'Hara, 1985; C. W. Eriksen \& Schultz, 1979). C. W. Eriksen argues that as information from a stimulus is being processed, there is a gradual priming of all possible responses. This partial activation of competing responses in a given task is common when the stimulus contains noise stimuli appropriate to these responses; "it is assumed that

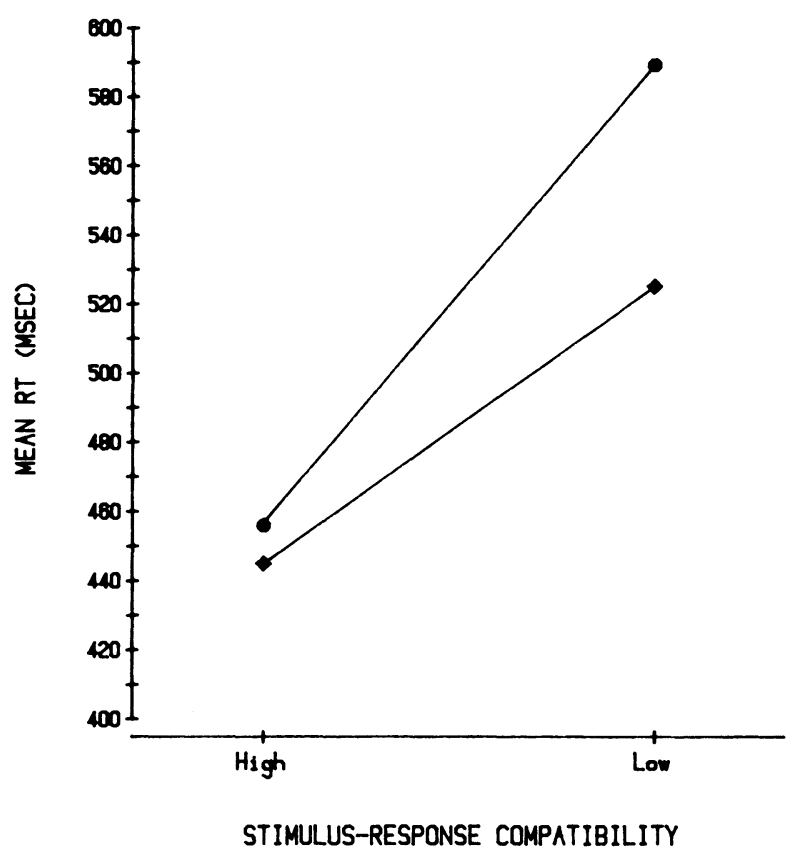

Figure 1. Mean RT to incongruent (circles) and congruent (squares) stimuli for conditions with high SRC and low SRC. 
this partial activation of competing responses delays the execution of the correct response"' (C. W. Eriksen et al., 1985, pp. 165-166). In the present context, it seems plausible to argue that the inhibition of competing responses will be more difficult when the response is highly compatible with the irrelevant dimension of the stimulus. This interpretation fits with current parallel models of information processing (e.g. C. W. Eriksen \& Schultz, 1979; Flowers \& Wilcox, 1982; Logan, 1980; McClelland \& Rumelhart, 1981). In Logan's (1980) model of the Stroop effect, evidence from different sources accrues over time in a composite decision process until a threshold is reached and a response emitted. Interference arises because of priming of competing responses. If the irrelevant dimension of a stimulus is associated with a particular response, this primed response will take time to inhibit and will slow reaction time.

Converging evidence for this view comes from research on dual-task interference showing that strong stimulus-response associations may be immune to interference. For example, two tasks can be performed simultaneously with little interference when different kinds of responses are called for. This multiprocessor approach (Allport, 1980; McLeod, 1977) suggests that dual-task interference can be eliminated when different response modalities access different processors for the two tasks (see Pashler, 1990, for critique of this approach). Such findings indicate the existence of "privileged loops" in the cognitive system; a word, for example, may bypass any translational mechanism and produce a phonological representation via a privileged loop (McLeod \& Posner, 1984). Such loops are considered to be separate from the general informationprocessing system, allowing for the performance of operations with relatively little interference from other cognitive activities. In the present context, these findings support the hypothesis that Stroop-like interference effects are at least partly determined by a high degree of compatibility between the irrelevant dimension of a stimulus and its response. If this relationship is highly natural or overlearned (e.g., a privileged loop), it would be very difficult for a subject to inhibit this response, which in turn will delay the execution of the correct response.

The present results replicate the findings of McClain (1983) and Zakay and Glicksohn (1985) for a different paradigm. It was shown that when both dimensions of a stimulus have compatible responses, the interference produced by stimulus incongruity varies depending on the degree of SRC. In accord with recent continuous models of information processing, it is suggested that Stroop-like interference may be due in part to the priming of a particular response by the irrelevant dimension of a stimulus. The stronger the compatibility of the irrelevant dimension with a response, the more difficult it is for the subject to inhibit this response, thus producing interference. It is concluded that these findings may only be applicable to automatized information-processing tasks. Stimulus congruity may be more important if the task requires substantial processing (e.g., Simon \& Sudalaimuthu, 1979) or if subjects are primed to use controlled processing strategies (e.g., Logan, 1980).

\section{REFERENCES}

AlLPORT, D. A. (1980). Attention and performance. In G. Claxton (Ed.), New directions in cognitive psychology (pp. 112-153). London: Routledge \& Kegan Paul.

BELLER, H. K. (1975). Naming, reading and executing directions. Journal of Experimental Psychology: Human Perception \& Performance, $1,154-160$

DYER, F. N. (1973). The Stroop phenomenon and its use in the study of perceptual, cognitive, and response processes. Memory \& Cognition, 1, 106-120.
ERIKSEN, B. A., \& ERIKSEN, C. W. (1974). Effects of noise letters upon the identification of a target letter in a nonsearch task. Perception \& Psychophysics, 16, 143-149.

Eriksen, C. W., Coles, M. G. H., Morris, L. R., \& O'Hara, W. P. (1985). An electromyographic examination of response competition. Bulletin of the Psychonomic Society, 23, 165-168.

ERIKSEN, C. W., AND Schultz, D. W. (1979). Information processing in visual search: A continuous flow conception and experimental results. Perception \& Psychophysics, 25, 249-263.

Flowers, J. H., \& DUTCH, S. (1976). The use of visual and name codes in scanning and classifying colors. Memory \& Cognition, 4, 384-390.

Flowers, J. H., Warner, J. L., \& Polansky, M. L. (1979). Response and encoding factors in "ignoring" irrelevant information. Memory \& Cognition, 7, 86-94.

Flowers, J. H., \& Wilcox, N. (1982). The effect of flanking context on visual classification: The joint contribution of interactions at different processing levels. Perception \& Psychophysics, 32, 581-591.

KEELE, S. (1972). Attention demands of memory retrieval. Journal of Experimental Psychology, 93, 245-248.

LogAN, G. D. (1980). Attention and automaticity in Stroop and priming tasks: Theory and data. Cognitive Psychology, 12, 523-553.

MacLEOD, C. M. (1991). Half a century of research on the Stroop effect: An integrative review. Psychological Bulletin, 109, 163-203.

MCCLaIN, L. (1983). Stimulus-response compatibility affects auditory Stroop interference. Perception \& Psychophysics, 33, 266-270.

McClelland, J. L., \& Rumelhart, D. E. (1981). An interactive activation model of context effects in letter perception: Part 1. An account of basic findings. Psychological Review, 88, 375-407.

MCLEOD, P. (1977). A dual task response modality effect: Support for multiprocessor models of attention. Quarterly Journal of Experimental Psychology, 29, 651-667.

McLeod, P., \& Posner, M. I. (1984). Privileged loops from percept to act. In H. Bouma \& D. G. Bouwhuis (Eds.), Attention and performance $X$ (pp. 55-56). Hillsdale, NJ: Erlbaum.

NeELY, J. H. (1991). Semantic priming effects in visual word recognition: A selective review of current findings and theories. In D. Besner \& G. W. Humphreys (Eds.), Basic processes in reading: Visual word recognition (pp. 264-336). Hillsdale, NJ: Erlbaum.

PASHLER, H. (1990). Do response modality effects support multiprocessor models of divided attention? Journal of Experimental Psychology: Human Perception \& Performance, 16, 826-842.

Semmes, J. S., Weinstein, L., Ghent, H., \& Teuber, H. (1963). Correlates of impaired orientation in personal and extrapersonal space. Brain, 86, 747-772.

Simon, J. R., \& Sudalaimuthu, P. (1979). Effects of S-R mapping and response modality on performance in a Stroop task. Journal of Experimental Psychology: Human Perception \& Performance, 5, 176-187.

STROOP, J. R. (1935). Studies of interference in serial verbal reactions. Journal of Experimental Psychology, 18, 643-662.

Treisman, A. M., \& Fearnley, S. (1969). The Stroop test: Selective attention to colours and words. Nature, 222, 437-439.

VIRZI, R. A., \& EGETH, H. E. (1985). Toward a translational model of Stroop interference. Memory \& Cognition, 13, 304-319.

ZAKAY, D., \& GLICKSOHN, J. (1985). Stimulus congruity and S-R compatibility as determinants of interference in a Stroop-like task. Canadian Journal of Psychology, 39, 414-423.

(Manuscript received March 26, 1992). 